\title{
Capítulo 04
}

Registros orais e escritos: um estudo com alunos e professores de educação de jovens e adultos ao solucionarem problemas de proporção-porcentagem

\author{
Idemar Vizolli \\ Maria Tereza Carneiro Soares
}

\section{SciELO Books / SciELO Livros / SciELO Libros}

VIZOLLI, I., and SOARES, MTC. Registros orais e escritos: um estudo com alunos e professores de educação de jovens e adultos ao solucionarem problemas de proporção-porcentagem. In: BRANDT, CF., and MORETTI, MT., orgs. Ensinar e aprender matemática: possibilidades para a prática educativa [online]. Ponta Grossa: Editora UEPG, 2016, pp. 85-117. ISBN 978-85-7798-215-8.

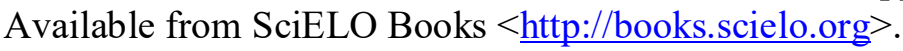

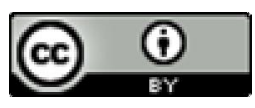

All the contents of this work, except where otherwise noted, is licensed under a Creative Commons Attribution 4.0 International license.

Todo o conteúdo deste trabalho, exceto quando houver ressalva, é publicado sob a licença Creative Commons Atribição 4.0.

Todo el contenido de esta obra, excepto donde se indique lo contrario, está bajo licencia de la licencia Creative Commons Reconocimento 4.0. 


\section{CAPÍTULO 04 \\ REGISTROS ORAIS E ESCRITOS: UM ESTUDO COM ALUNOS \\ E PROFESSORES DE EDUCACÃO DE JOVENS E ADULTOS \\ AO SOLUCIONAREM PROBLEMAS DE PROPORÇ̃O- \\ PORCENTAGEM}

Idemar Vizolli

Maria Tereza Carneiro Soares

\section{O DESCORTINAR DO OBJETO DE PESQUISA}

Uma das formas de tematizar a realidade é buscar em nossa história de vida elementos que nos instigaram ou intrigaram, ou que nos despertaram desejos ou frustrações e que resultam em problemas para os quais não temos solução e que talvez nem cheguemos a tê-la. De qualquer forma, são perguntas para as quais ainda não encontramos respostas ou curiosidades ainda não satisfeitas.

$\mathrm{Na}$ pesquisa que originou este trabalho voltamos nosso olhar para o ensino da matemática. Queríamos saber, especificamente, como pessoas sem escolarização ou pouco escolarizadas solucionam problemas de matemática em seu contexto social imediato e quais estratégias utilizam para solucionar problemas que lhes são propostos em situação escolar.

No trabalho e em muitas situações da vida cotidiana, precisamos analisar dados e informações que são apresentados por meio de gráficos, tabelas ou índices e, por meio delas. é preciso tomar decisões. Muitas vezes as análises necessárias dependem de conhecimentos de proporção-porcentagem. A compreensão de tal conceito pode fazer a diferença entre ser ou não ser ludibriado 
por propagandas enganosas ou dados e informações distorcidas. Além disso, a proporção-porcentagem é de grande aplicabilidade em situações não só da vida cotidiana das pessoas (como cálculo de salários ou transações comerciais e financeiras), mas também em outras áreas do conhecimento, como na física, na biologia na química, na estatística, entre outras.

Ao tratar de proporção-porcentagem, é possível encontrar uma série de outros conceitos e relações, como, por exemplo, a multiplicação, a divisão, a razão, a fração e a comparação. Neste processo, pode ser relevante também a compreensão de outros conceitos matemáticos, como os de equação e função. Isso possibilita que se pense a proporção-porcentagem como objeto de estudo e não somente como uma "ferramenta" que existe em função de sua aplicabilidade.

Pesquisadores como Fonseca (2001, 2002), Carraher e Schliemann (1988), Carvalho (1995), entre outros, indicam que pessoas pouco escolarizadas, que sabem solucionar alguns dos problemas de seu contexto social, não veem relação entre o que fazem com os conhecimentos matemáticos de que necessitam para ter sucesso na escola. Acreditamos que muitos professores possuem dificuldades em identificar a relação entre os conhecimentos matemáticos implicados na solução dos problemas e a matemática escolar. Ainda que consigam fazê-lo, dificilmente reconhecem a relevância de se estabelecer essa relação para o aprendizado da estratégia escolar e, mais ainda, para ampliá-la e aprimorá-la.

Além de saber como as pessoas adultas solucionam problemas de matemática em seu contexto social é importante que os professores de matemática identifiquem os conhecimentos matemáticos não escolares apresentados nessas soluções, para que possam utilizar tais conhecimentos como forma de valorização do que é produzido socialmente. Acreditamos ainda que se os professores utilizarem os diferentes registros de representação semiótica como ponto de partida e de ancoragem para a proposição e para o desenvolvimento de atividades, auxiliarão os alunos a ampliarem os conhecimentos que estes já possuem.

O processo de ensino e aprendizagem na Educação de Jovens e Adultos (EJA), talvez mais que nas demais modalidades educativas, precisa levar em 
conta os conhecimentos que os sujeitos já apresentam, possibilitando aos alunos condições para que atribuam significados não só às representações com que se deparam em seu contexto social, mas também àquelas convencionais e que se fazem presentes nas mais diferentes formas de comunicação.

\section{O REVELAR DO OBJETO INVESTIGADO}

Ao analisar as pesquisas na área, principalmente aquelas voltadas à educação matemática na EJA, percebemos que autores como Duarte (1987), Carraher, Carraher e Schliemann (1988), Carvalho (1995), Fonseca (2001; 2002), entre outros, compartilham da ideia de que os alunos possuem conhecimentos de matemática oriundos de seu contexto social mais imediato e que as estratégias ali utilizadas na solução de problemas diferem daquelas comumente empregadas no processo de escolarização.

Embora os professores reconheçam que os alunos ancoram seus raciocínios em situações relacionadas a sua vida prática, raciocínios úteis em espaços sociais que não a escola, pouco se tem refletido sobre o modo como os alunos e mesmo os professores de EJA escrevem a solução de problemas de proporção-porcentagem e muito menos sobre os registros de representação que são utilizados no processo de solução de tais problemas. Poucas vezes os professores exploram, para fins de conceitualização dos objetos matemáticos, o modo como os alunos solucionam os problemas "ensinados" no processo de escolarização.

Fonseca (2001) observou que os professores de EJA tendem a interpor resistência às reminiscências das experiências escolares anteriores dos alunos, muitas vezes ignorando-as ou até mesmo reprimindo-as, o que sugere uma certa insensibilidade ou despreparo que não lhes permite reconhecê-las e muito menos integrá-las à dinâmica do processo de ensino e aprendizagem atual. O autor (2001, p. 5) observa, ainda, que há por parte de alguns professores "uma má vontade confessa em relação aos conhecimentos escolares prévios dos alunos que se 're-escolarizaram', que busca justificar-se colocando sob suspeita a qualidade dessa experiência escolar pregressa - que resultou em 'fracasso' e 'abandono'”. Segundo Fonseca (2001, p. 6), “a escola que, ao menos no nível do discurso, já reconhece como significativa a experiência de vida 
do aluno, descarta, no entanto, sua experiência de vida escolar, renegando-a ou, simplesmente, ignorando-a, caso ela não se restrinja e corresponda aos pré-requisitos já estabelecidos para o 'avanço' da matéria”.

A experiência docente que tivemos na EJA permite-nos dizer que tais resistências se manifestam muito mais quando a proposta pedagógica não é ou não foi devidamente pensada, discutida, elaborada e implementada pelo coletivo do corpo docente que atua ou vai atuar na EJA. Isso não significa dizer que não há resistências. O grande desafio para os professores, principalmente de matemática, reside na superação das limitações advindas da falta de conhecimentos sobre a forma de ensinar matemática e sobre a forma como alunos adultos estruturam seu pensamento para solucionar problemas trabalhados no contexto de sala de aula.

Nossas vivências e experiências profissionais têm mostrado que os alunos de EJA, quando estimulados, são capazes de expressar a forma como organizaram os dados e as informações presentes no enunciado do problema. No entanto, o fazem com mais desenvoltura através da oralidade e não pela escrita - o que não significa dizer que não se utilizem de raciocínios organizados.

O exercício da docência tem indicado que uma das dificuldades dos alunos de EJA em efetuar registros de representação em matemática (se não a maior delas) reside na falta de conhecimentos das regras de significado e funcionamento da linguagem desta disciplina. A linguagem matemática, assim como as demais formas de comunicação em que se faz uso de signos, necessita de regras para que a mensagem possa ser comunicada a outrem. O domínio das "regras de significado e funcionamento", em toda forma de linguagem escrita, seja ela em "língua natural", numérica, algébrica, entre outras, não é uma tarefa trivial para os alunos - muitas vezes nem para os professores (DUVAL, 1993; 1995).

Os professores, diferentemente dos alunos, estão permanentemente em contato com diferentes formas de comunicação por meio de escrita. Mesmo aqueles que não ensinam matemática fazem uso dela para explicar determinadas situações ou conceitos da disciplina que lecionam. Além disso, frequentaram ou frequentam o processo de escolarização formal, quer em cursos de 
graduação, quer de pós-graduação, quer em cursos de formação continuada. Esse contato sistemático com diferentes formas de comunicação por meio da escrita constitui-se num elemento facilitador para o acesso a quaisquer regras de significado e funcionamento, inclusive da linguagem matemática.

Como os professores são indispensáveis ao processo de escolarização e como uma de suas principais tarefas é propiciar as condições para que os alunos ampliem sua gama de conhecimentos - o que exige, principalmente, a utilização de registros que obedeçam a regras de significado e funcionamento -, é fundamental (também para o ensino de matemática) que eles utilizem diferentes registros de representação. Não só isso, é preciso fazer a conversão dos registros de representação em sistemas semióticos diferentes, para que os alunos passem a se familiarizar com eles, de modo a perceber que o uso variado da linguagem matemática permite o desenvolvimento de um pensamento matemático mais flexível. Assim, a metodologia utilizada pelo professor, aliada a sua postura perante o conhecimento, pode fazer a diferença no processo de escolarização.

Esse panorama nos permitiu estabelecer os seguintes objetivos:

a) Identificar os conhecimentos matemáticos que são mobilizados pelos professores e alunos de um curso de EJA ao solucionarem problemas de proporção-porcentagem.

b) Identificar os registros verbais escritos utilizados pelos professores e alunos desse mesmo curso ao solucionarem esses mesmos problemas.

\section{APORTAR NO REFERENCIAL TEÓRICO: REGISTRO DE REPRESENTAÇÃO SEMIÓTICA}

Pesquisadores em educação matemática, como Almouloud (2003), Bittar (2003), Damm (1992; 1999; 2003), Freitas (2003), Maranhão e Igliori (2003), Nehring (2001), entre outros, têm desenvolvido pesquisas sobre a forma como se processa a aprendizagem de conhecimentos matemáticos, com base na teoria proposta por Duval (1993; 1995; 2003).

Para esses autores, em matemática toda comunicação se estabelece com base nas representações dos objetos a serem estudados. Há consenso entre 
eles de que os objetos matemáticos são conceitos, propriedades, estruturas e relações que expressam diferentes situações de modo que, para seu ensino, é preciso levar em consideração as diferentes formas de representação de um mesmo objeto.

De acordo com Duval (1993), um objeto matemático não é algo pronto, acabado, mensurável ou fisicamente observável. Ele é composto por estruturas ou relações que podem expressar diferentes situações, por isso é preciso considerar as diferentes formas de representá-lo. Muitas vezes o professor de matemática lança mão de recursos didáticos demonstrativos, visuais ou manipulativos, que nem sempre auxiliam o aluno a expressar certas situações matematicamente. No entanto, é indispensável que o professor tenha clareza da diversidade de registros de representação semiótica, além de seus respectivos tratamentos e conversões, coordenando assim as transformações entre eles.

Para o autor (1993; 1995; 2003), o tratamento é a transformação de uma representação de partida em uma representação de chegada dentro de um mesmo registro (DUVAL, 1995, p. 40). A conversão, por sua vez, é a transformação de um sistema de representação semiótica para outro sistema igualmente semiótico (DUVAL, 1993; 1995; 2003). Ela é uma transformação externa ao registro de representação de partida.

Para Duval, (1993, p. 38), "as representações semióticas são produções constituídas pelo emprego de signos pertencentes a um sistema de representação, as quais têm suas construções próprias de significado e funcionamento". Elas se caracterizam por "um sistema particular de signos, a linguagem, escrita algébrica ou os gráficos cartesianos, e que podem ser convertidos em representações equivalentes dentro de outro sistema semiótico, mas podem apresentar significados diferentes para o sujeito que as utiliza" (DUVAL, 1995, p. 17).

De acordo com o autor (2003), as representações semióticas são fundamentais, primeiramente pela existência de diversas possibilidades de tratamento matemático, além disso, pelo fato de os objetos matemáticos não serem diretamente perceptíveis ou observáveis sem a ajuda de instrumentos.

Ao tratar do ato de construção do conhecimento, Duval (1993; 1995) estabelece três tipos de perspectivas para o termo representação: representações 
mentais, representações internas ou computacionais e representações semióticas.

As representações mentais têm função de objetivação, portanto, são internas e conscientes, ocorrendo no nível do pensamento, daquilo que se tem em mente. Elas estão no mesmo patamar das concepções prévias acerca de determinados fenômenos ou fatos, incluem também as fantasias criadas durante a infância. Segundo Duval (1993, p. 38), as representações mentais "recobrem um conjunto de imagens e, mais globalmente, as concepções que o indivíduo tem sobre um objeto, sobre uma situação ou sobre alguma coisa a que está associado”. Elas estão relacionadas ao método da conversão.

As representações internas ou computacionais, por sua vez, estão relacionadas ao tratamento e se caracterizam pela execução automática de uma determinada tarefa. As representações mentais são internas e não conscientes. O sujeito apenas as executa, utilizando-se de regras, macetes, fórmulas ou esquemas, sem pensar em todos os passos lógicos. A noção de representação interna é fundamental porque permite mudar a forma de acordo com o nível de tratamento considerado. As representações computacionais traduzem as informações externas de um sistema, em uma forma que seja possível recuperá-las e combiná-las em seu interior. Referem-se a teorias que privilegiam um tratamento no qual a noção de representação é concebida como uma representação interna ou computacional. O tratamento está ligado à forma como se apresenta determinada informação ou determinado conceito e não a seu conteúdo.

Muitas vezes as representações mentais não passam de representações semióticas interiorizadas. As representações mentais úteis ou pertinentes em matemática são sempre representações semióticas interiorizadas, em interação com um tratamento de produção externa de representações semióticas (DUVAL, 2003, p. 31). As representações semióticas dependem das representações mentais e computacionais. Ao mesmo tempo, tais representações realizam, sucessivamente, funções de objetivação e tratamento - lembrando que o tratamento não é automático e sim intencional, o que é fundamental para a aprendizagem humana (DUVAL, 1995). 
As representações semióticas pressupõem que se leve em consideração a existência de diferentes sistemas semióticos, permitindo, assim, a operação cognitiva de conversão das representações entre os diferentes sistemas semióticos.

Para Duval (1993; 1995), existem três atividades cognitivas de representação inerentes à semiósis: a formação, o tratamento e a conversão. A formação de uma representação constitui um registro semiótico particular, seja para exprimir uma representação mental ou um objeto real. De qualquer forma, ela implica sempre a seleção das características e determinações que constituem o que se quer representar. A formação de uma representação semiótica exige a utilização de signos que possam expressar o objeto e até mesmo mudar de registro. As representações idiossincráticas e as notações que dão nome aos objetos não se caracterizam como registros de representação semiótica. Estes, necessariamente, têm que respeitar as regras do sistema utilizado, não somente para fins de comunicabilidade, mas principalmente, para tornar possível a utilização de modos de tratamento.

Nas representações idiossincráticas, predominam as regras de produção, enquanto nos registros de representação semiótica levam-se em consideração as regras de conformidade. Segundo Duval (1995), são as regras de conformidade que definem um sistema de representação e os tipos de unidades constitutivas de todas as representações possíveis de um registro. Elas também identificam um conjunto de elementos físicos ou traços como sendo uma representação de alguma coisa.

O tratamento dado a um determinado objeto depende da forma adotada para representá-lo e não do conteúdo ao qual está vinculado o conhecimento. Segundo Duval (1993), um objeto representado não deve ser confundido com o conteúdo da representação, sob o risco de não dar conta da real diferença que existe entre duas ou mais representações de um mesmo objeto. O conteúdo da representação depende em parte da forma, uma vez que o conteúdo do registro é que permite explicitar o objeto representado.

As representações mentais, as representações computacionais e as representações semióticas não são espécies diferentes de representação, 
uma vez que estão imbricadas, ainda que realizando trabalhos diferentes. De outra maneira, podemos dizer que as representações podem ser convertidas em representações similares ou equivalentes num outro sistema semiótico, podendo ter significados diferentes para as pessoas que o utilizam.

No ensino e na pesquisa - e em especial na educação matemática - temos de lembrar que estamos lidando com objetos, na maioria das vezes abstratos, algo que não é manipulável, pronto, acabado ou fisicamente observável e que, portanto, pode ter vários significados. Temos em nossas mãos estruturas ou relações que podem expressar diferentes situações ou fatos que não são acessíveis à percepção, necessitando de uma representação, que é a base da comunicação, uma vez que expressa o conhecimento que se tem de um objeto de estudo, constituindo-se em uma expressão escrita.

Gráficos, símbolos, figuras, fórmulas, desenhos, conceitos e outros são representações significativas, uma vez que a sua utilização permite a comunicação entre as pessoas e as atividades cognitivas do pensamento, garantindo diferentes registros de representação para um mesmo objeto matemático.

Quando se trabalha com problemas, por exemplo, o fundamental não são os desenhos que podem ser feitos a partir do enunciado, nem mesmo as operações matemáticas envolvidas, mas sim o entendimento que se deve estabelecer entre o enunciado, a representação intermediária e o tratamento matemático, uma vez que este objeto não é claro e acessível como os objetos físicos - exatamente por isso, seu tratamento depende de uma representação semiótica. Segundo Duval (1993, p. 38), “as representações (semióticas) não são somente necessárias para fins de comunicação; elas são igualmente essenciais para as atividades cognitivas do pensamento".

Como se vê, as representações semióticas não são apenas exteriorização das representações mentais necessárias para se estabelecer uma comunicação, uma vez que o indivíduo que aprende necessita delas também para elaborar o conhecimento. Portanto, elas desempenham funções de cognição (tratamento, conversão e representação).

Para Duval (2003), a utilização de vários registros de representação propicia o desenvolvimento do conhecimento humano e possibilita a criação 
de novos sistemas semióticos, a exemplo da evolução nos sistemas de numeração utilizados pela humanidade no decorrer do tempo. O progresso dos conhecimentos é oriundo da criação e do desenvolvimento de novos e mais específicos sistemas semióticos, resultados do trabalho com vários registros de representação. A criação de novos registros está diretamente relacionada às necessidades da espécie humana. Daí as diferentes bases do sistema de numeração, os números fracionários, os decimais, a porcentagem e tantas outras criações.

\section{A PROPORÇÃO-PORCENTAGEM E SEUS REGISTROS DE REPRESENTAÇÃO}

Duval (2003, p. 14) classificou os registros de representação semiótica em quatro tipos muito diferentes, conforme consta do Quadro 1. Neste quadro, apresentamos em itálico os registros de representação semiótica que devem ser mobilizáveis no fazer matemático de proporção-porcentagem (VIZOLLI, 2001; 2006).

Quadro 1 - Classificação dos diferentes registros mobilizáveis no funcionamento matemático (fazer matemático, atividade matemática)

\begin{tabular}{|c|c|c|}
\hline & Representação discursiva & Representação não-discursiva \\
\hline $\begin{array}{l}\text { Registros } \\
\text { multifuncionais: } \\
\text { os tratamentos } \\
\text { não são } \\
\text { algoritmizáveis }\end{array}$ & $\begin{array}{l}\text { - Língua natural } \\
\text { - Associações verbais } \\
\text { (conceituais) } \\
\text { - Forma de raciocinar } \\
\text { - Argumentação a partir de } \\
\text { observações, de crenças } \\
\text { - Dedução válida a partir de } \\
\text { definição ou de teoremas } \\
\text { - Registro verbal oral }\end{array}$ & $\begin{array}{l}\text { - Figuras geométricas planas ou } \\
\text { em perspectivas (configurações } \\
\text { em dimensão } 0,1,2 \text { ou } 3 \text { ) } \\
\text { - Apreensão operatória e não } \\
\text { somente perceptiva } \\
\text { - Construção com instrumentos } \\
\text { - Figura geométrica }\end{array}$ \\
\hline $\begin{array}{l}\text { Registros } \\
\text { monofuncionais: } \\
\text { os tratamentos } \\
\text { são } \\
\text { principalmente } \\
\text { algoritmos }\end{array}$ & $\begin{array}{l}\text { - Sistemas de escritas } \\
\text { - Numéricas (binária, decimal, } \\
\text { fracionária etc.), algébricas e } \\
\text { simbólicas (línguas formais) } \\
\text { - Cálculo } \\
\text { - Registro verbal escrito numérico } \\
\text { (percentual; fracionário; decimal; } \\
\text { tabela de proporcionalidade)e } \\
\text { aritmético. } \\
\text { - Equação } \\
\text { - Função }\end{array}$ & $\begin{array}{l}\text { - Gráficos cartesianos } \\
\text { - Mudanças de sistema de } \\
\text { coordenadas } \\
\text { - Interpolação e extrapolação } \\
\text { - Gráfico cartesiano }\end{array}$ \\
\hline
\end{tabular}

Fonte: os autores 
Devemos notar que, nos registros multifuncionais, os tratamentos não são algoritmizáveis. Além disso, têm como representação discursiva a língua natural, isto é, se manifestam por meio de associações verbais ou de raciocínios argumentativos ou dedutivos.

Os discursos dedutivos tomam como base as definições, as propriedades, os teoremas, entre outros, respeitando as regras da organização do discurso matemático. A passagem de uma afirmação para outra é feita com referência às regras que as justificam. Os discursos argumentativos se apoiam, principalmente, em observações e crenças, seguindo o princípio da linguagem natural. Nesse tipo de discurso existe o encadeamento semântico, no qual as afirmações vão sendo agrupadas e não se exigem regras predefinidas. Estes registros também podem aparecer na forma não-discursiva, a exemplo das configurações geométricas. Nos registros monofuncionais os tratamentos são algoritmizáveis e têm como representação os sistemas de escrita. Eles podem aparecer também de forma não discursiva, a exemplo dos gráficos cartesianos.

Ao apresentar os registros de representação semióticas necessários ao processo de conceitualização de proporção-porcentagem tomamos como exemplo o problema 1, que faz parte dos Estudos II, III e IV da pesquisa que resultou nesta tese.

Em 2003, o salário mínimo era de $R \$ 200,00$. Se tivesse sofrido um aumento de $30 \%$, de quantos reais teria sido o aumento?

a) Registro verbal oral - Trata-se da fala do participante. Ao executar o registro verbal oral o sujeito pensa sobre o objeto em questão. A fala sobre o objeto em estudo auxilia o professor-pesquisador a perceber se o aluno consegue identificar as variáveis em jogo, as quantidades e a incógnita, assim como as relações estabelecidas ou não. No caso da proporção-porcentagem é possível identificar a relação que os alunos estabelecem com a centena. É possível verificar, também, que se estabelecem relações entre a pergunta do problema e o resultado obtido. Em suma, o registro verbal oral oferece elementos para que se possa perceber se o sujeito compreende o significado da questão proposta. Ao se tratar de EJA, o registro verbal oral pode se constituir numa valiosa fonte de informações para que os professores possam conhecer o que os alunos já sabem sobre o objeto de estudo. 
Tomando como exemplo o problema indicado, é possível obter respostas como esta: "eu sei que o aumento é de sessenta reais, mas não sei fazer a conta". Neste caso, "fazer a conta", significa efetuar registros escritos utilizando-se exclusivamente de símbolos ou algoritmos matemáticos.

b) Registro verbal escrito - Como o sujeito que o executa faz uso de regras gramaticais da língua materna para expressar as informações necessárias e indicar a incógnita, denominamos este registro verbal escrito. Assim como no registro verbal oral, esse registro não garante que o sujeito reconheça o objeto representado num registro matemático. Muitas vezes, os alunos utilizam o registro verbal escrito combinado com o registro de representação numérico. Neste caso, podemos dizer que se trata de um registro de representação semiótica misto.

Uma forma de atribuir sentido e significado operatório para solucionar o problema utilizado como exemplo é tomar como ponto de partida a taxa percentual (30\%), que significa 30 de cada 100. Como o salário era de 200, então o aumento seria de 60 . Esta resposta indica a compreensão do valor relativo da taxa percentual; é possível, pela adição de parcelas iguais ou pela multiplicação, encontrar o resultado matemático, o que possibilita responder à pergunta do problema.

c) Registro de representação numérico - Neste tipo de registro, o sujeito opera com os dados fornecidos pelo enunciado do problema, sem necessariamente se dar conta da possibilidade da existência de um registro algébrico. Neste tipo de registro, não necessariamente o sujeito busca apoio ou referência fora do contexto do enunciado do problema, ou seja, ele já consegue estabelecer relações entre os dados e operar algoritmicamente. Assim o sujeito opera com os dados fornecidos pelo enunciado do problema, sem necessariamente se dar conta da possibilidade da existência de um registro algébrico. Em nossa dissertação de mestrado (VIZOLLI, 2001) destacamos que cada um dos registros de representação numérico possui especificidades, embora obedeçam a determinadas regras de significado e funcionamento como, por exemplo, as da base dez. O registro de representação numérico pode aparecer de diferentes formas: fracionária, percentual, tabela de números proporcionais, decimal e aritmético. 
Para exemplificar cada uma das variações do registro de representação numérico, tomamos como referência o problema 1 (já mencionado), no qual temos:

i) Fracionário $30 / 100$ de $200=3 / 10$ de 200

ii) Percentual $30 \%$ de 200

iii) Tabela de números proporcionais

\begin{tabular}{c|c} 
Taxa & Quantidade de referência \\
\hline 30 & 100 \\
60 & 200
\end{tabular}

iv) Decimal 0,3 de 200

v) Aritmético $(200.30): 100=60$ ou $(200: 100) .30=60$

É importante que se note que é possível encontrar registros de representação numérico com números fracionários $(200.30 / 100=6000: 100=$ 60 ) ou decimais $(200 \cdot 0,3=60)$.

No registro de representação em tabela de números proporcionais, o sujeito reconhece a relação entre a taxa percentual e a centena, alinhando seus valores absolutos em colunas que representam quantidades distintas (quantidade inicial - qi - e quantidade de transformação - qt) e depois organizando os dados numa tabela constituída por duas colunas. A utilização do registro de representação na forma de tabela facilita a compreensão e a construção do registro de representação na forma de gráfico cartesiano (VIZOLLI, 2001).

Trata-se de estabelecer a relação entre a taxa percentual e a centena, para depois comparar esta relação, com a quantidade inicial fornecida pelo enunciado do problema, com sua respectiva taxa percentual. Assim, 30\% é 30 de 100 , como são $R \$ 200,00$, então são $R \$ 60,00$. Quando solicitado que se efetue, no papel, o registro do procedimento utilizado, podemos encontrar também o registro de representação misto. No registro de representação por tabela de números proporcionais, muitas vezes o sujeito consegue perceber as relações verticais e horizontais, por isso, esse pode ser considerado um registro mais elaborado que o registro numérico aritmético. 
d) Registro de representação geométrico - Este tipo de registro pode ser efetuado com o desenho de uma figura geométrica representando a centena, por exemplo, na qual se destaca a parte correspondente à taxa percentual. Ao se tratar de registro geométrico é importante fazer a conversão passando pelo fracionário e, se for o caso, a equivalência das frações, chegando ao denominador 100, o que facilitará a percepção da porcentagem.

No caso do problema utilizado como exemplo, podemos efetuar o seguinte registro, no qual cada célula corresponde a 10 unidades e cada célula destacada corresponde a $10 \%$.

\begin{tabular}{|l|l|l|l|l|l|l|l|l|l|}
\hline & & & & & & & & & \\
\hline & & & & & & & & & \\
\hline
\end{tabular}

e) Registro de representação na forma de gráfico cartesiano - Este registro de representação pode conter variações: gráfico cartesiano, gráfico de setor, gráfico por linhas ou colunas. De qualquer forma, o registro gráfico exige que o sujeito controle, pelo menos, duas variáveis, além do que, ele precisa perceber a proporção, para indicar os respectivos pares ordenados. Este registro de representação semiótica pode possibilitar ao sujeito perceber a proporção e identificar a lei de formação da função.

O exemplo que estamos utilizando pode ser representado pelo gráfico de colunas a seguir.

Figura 1 - Gráfico de colunas representando porcentagem

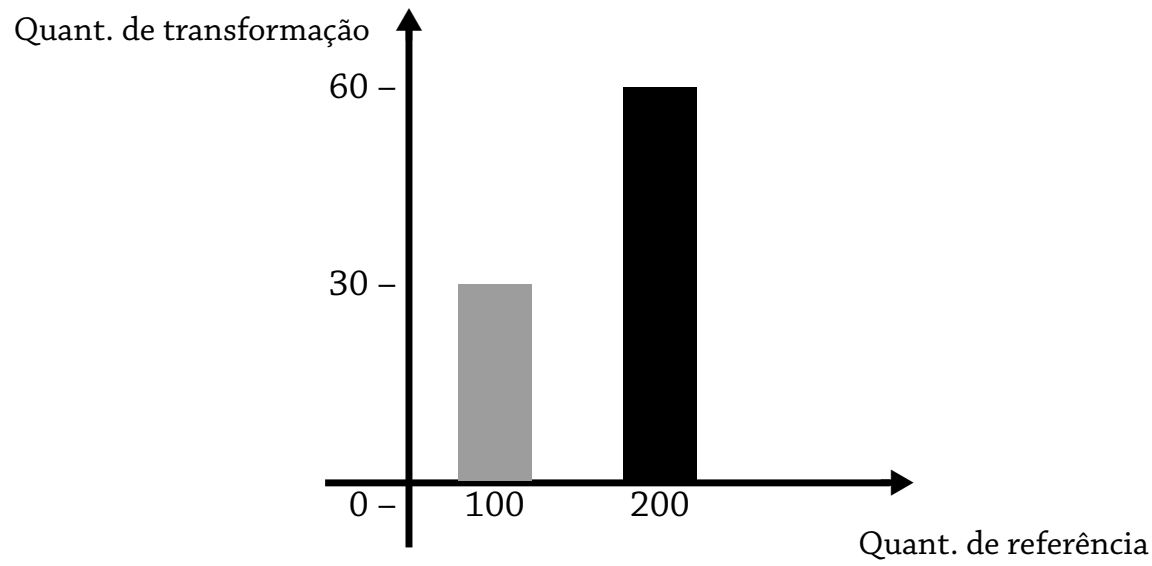


f) Registro de representação por equação - É constituído por uma sentença matemática aberta, expressa por uma igualdade. Trata-se de uma representação algébrica em que " $\mathrm{x}$ " se constitui na incógnita e assume um único valor.

No caso do problema utilizado como exemplo, é preciso estabelecer as devidas relações entre as quantidades, reconhecendo a taxa percentual como um valor relativo. Assim, 30\% é 30 de cada 100. Como o problema fornece a quantidade de referência (200), há que se estabelecer as devidas relações. Isso exige o reconhecimento da propriedade fundamental da proporção: o produto dos meios é igual ao produto dos extremos, o que pode ser organizado numa tabela, da seguinte forma:

Ao aplicar a propriedade fundamental da proporção o sujeito se depara com a aplicação da regra de três.

\begin{tabular}{l|l} 
Taxa & Quantidade de referência \\
\hline 30 & 100 \\
$x$ & 200 \\
$30.200=100 \cdot x$ & \\
$6000=100 x$ \\
$6000: 100=x$ \\
$x=60$
\end{tabular}

g) Registro de representação por função - Também pode ser visto como um modelo matemático. Neste caso, o procedimento utilizado leva o sujeito a tratar com as regras de significado e funcionamento do tratamento dispensado à função. O sujeito que o executa consegue estabelecer as devidas relações entre os dados e as informações contidas no enunciado do problema, delimitando generalizações que o permitem operar algebricamente, inclusive estabelecendo um modelo matemático. Damm (1998) apresentou um modelo que pode ser utilizado aqui. Vejamos: qt $=($ qi $\times \mathrm{p}): 100$

Para o problema utilizado como exemplo, temos o seguinte modelo:

$$
\begin{aligned}
& \mathrm{qt}=(200,00 \times 30): 100 \\
& \mathrm{qt}=6000,00: 100 \\
& \mathrm{qt}=60,00
\end{aligned}
$$


A partir da taxa percentual, também é possível estabelecer a função. Neste caso, tem-se uma taxa de $30 \%$, a qual é utilizada para estabelecer uma lei matemática ou função. Assim, $\mathrm{f}(\mathrm{x})=30 \% \mathrm{x}$ ou $\mathrm{f}(\mathrm{x})=30 \mathrm{x} / 100$ ou $\mathrm{f}(\mathrm{x})=0,3 \mathrm{x}$, onde $f(x)$ é quantidade de transformação e " $x$ ", a quantidade referência.

\section{PROCEDIMENTOS METODOLÓGICOS PARA A REALIZAÇÃO DA PESQUISA}

Com o objetivo de identificar os registros de representação que são utilizados por alunos de EJA para solucionar problemas de proporção-porcentagem, no Estudo I solicitamos que três alunos do $3^{\circ}$ Ciclo de aprendizagem (equivalente à $5^{\mathrm{a}}$ e $6^{\mathrm{a}}$ séries do segundo segmento do Ensino Fundamental) solucionassem, individualmente, três problemas tomados do pós-teste da pesquisa anterior (VIZOLLI, 2001) ${ }^{1}$.

O Estudo IV foi desenvolvido com quatro duplas de alunos do $4^{\circ}$ Ciclo de aprendizagem do EJA, no qual, em entrevista, solicitou-se que os participantes solucionassem três problemas.

Problema 1 - Em 2003, o salário mínimo era de $R \$ 200,00$. Se tivesse sofrido um aumento de $30 \%$, de quantos reais teria sido o aumento?

Problema 2 - Um trabalhador recebe um salário de $R \$ 500,00$ e está defasado em $R \$ 200,00$. Expresse essa defasagem na forma de taxa percentual.

Problema 3 - O trabalhador de uma empresa que recebe salário tem direito ao Fundo de Garantia por Tempo de Serviço (FGTS), que é de 8\% sobre o salário bruto (salário bruto é o valor total da folha de pagamento). Sabendo que o valor do FGTS que a empresa tem que depositar mensalmente é de $R \$ 40,00$, qual é o valor do salário bruto desse trabalhador?

A coleta de dados foi realizada no mês de setembro de 2004 e as entrevistas foram totalmente gravadas em áudio e depois transcritas.

Antes da realização das entrevistas com as quatro duplas de alunos, foram informados os objetivos da pesquisa e o método a ser utilizado. Cada

\footnotetext{
${ }^{1}$ Para obter mais informações sobre tais problemas, sugerimos a leitura de VIZOLLI (2001; 2006). Os procedimentos metodológicos adotados nos estudos I, II e III, estão disponíveis na bibliografia de 2006.
} 
uma das duplas de alunos foi encaminhada pela professora mediadora ${ }^{2}$, de acordo com a ordem com que iam concluindo as atividades que estavam sendo desenvolvidas em sala de aula.

Em todas as entrevistas, à medida que os problemas iam sendo propostos, o pesquisador ou mesmo um dos participantes fazia a leitura de cada um, para que fossem esclarecidas possíveis dúvidas quanto ao entendimento dos dados e informações.

Neste trabalho, apresentamos as análises relativas aos registros de representação semiótica utilizados pelos participantes do Estudo IV - ou seja, os registros orais e escritos utilizados pelos participantes de quatro duplas de alunos de $4^{\circ}$ Ciclo de Aprendizagem (equivalente a $7^{\mathrm{a}}$ e $8^{\mathrm{a}}$ séries do Ensino Fundamental).

\section{ANÁLISE DOS DADOS}

\section{Primeira dupla: EPm(22;11) e LAf(35;5)}

O pesquisador fez a leitura do problema 1. Passados alguns minutos, os alunos registram, em suas respectivas folhas, as seguintes operações:

$\operatorname{EPm}(22 ; 11)$

$$
\begin{gathered}
00,20 \\
\times \quad 30 \\
\hline 00,00 \\
00,60- \\
\hline 006,00
\end{gathered}
$$

\section{LAf $(35 ; 5)$}

$18 \lcm{30}$

$\underline{-18} 6,00$

Os registros verbais escritos indicam que os participantes buscaram um algoritmo para solucionar o problema. No entanto, eles não dominam as regras de significado e de funcionamento a que se refere Duval (1993). Esses registros são constituídos por números e representam operações fundamentais - neste caso, multiplicação e divisão, respectivamente. Referem-se a registros

\section{de representação semiótica numérico aritméticos.}

Ao ser questionado pelo pesquisador como havia pensado para chegar aos $\mathrm{R} \$ 60,00, \operatorname{LAf}(35 ; 5)$ respondeu: pegar esse 200 e dividir por 30 pra saber este aumento. Enquanto o pesquisador dialogava com LAf(35;5), EPm(22;11)

\footnotetext{
${ }^{2}$ No EJA/Univali, trata-se de um professor que permanece em sala de aula com os alunos. Ele coordena e articula as atividades com os alunos e os professores das diferentes áreas do conhecimento.
} 
acompanhava. Quando o pesquisador referiu-se a ele, ele falou: eu fiz 200 vezes 30 . Ao ser questionado sobre o valor encontrado, que dizia ter sido 600 , e não 6,00 conforme registro da operação matemática efetuada, afirmou que tinha dúvidas, uma vez que 600 é muito alto.

LAf $(35 ; 5)$ voltou a refletir sobre os dados apresentados no enunciado, dizendo: Se aumento 30\%? Recorreu a $10 \%$ de 200 , mas a resposta não veio. O pesquisador propôs uma revisão perguntando a $\operatorname{EPm}(22 ; 11)$ : O que significa 30\%? O que quer dizer 30\%? Mesmo assim, a resposta não veio. $\mathrm{O}$ pesquisador insistiu: Não posso dizer que é 30 de cada 100? LAf(35;5) entrou na conversa e disse: Pode, porque é porcentagem. EPm(22;11) tentou se convencer e falou: Por 100. Cada 100 pode 30. Em seguida respondeu: São 60. Resposta esta que veio junto com a resposta de LAf(35;5): 60. As conversas que se seguiram confirmam o que foi dito anteriormente em relação às regras de significado e funcionamento (Duval 1993; 1995) dos registros de representação matemática.

Mais adiante, o pesquisador perguntou: de que maneira podemos fazer uma conta, para chegar aos $R \$ 60,00$ ? Durante os diálogos, os participantes foram compondo os dados e informações e encontraram uma forma de chegar ao resultado. Isso pode ser visto nos trechos das transcrições dos protocolos que seguem.

P - Tá. Fala pra mim, como é que você organizaria de cabeça, 30\% de 200? LAf(35;5) - Eu faria assim: 10\% né. 10\% de 200 eu sei que vai dá 20. $P-O K$.

LAf(35;5) - Mais 20\%, daria 40, mais 30\%, seria 60\%. Aí, 10, 10, 10, seria 60, aliás, 20, 20, 20 daria 60.

$P$ - Ok. Então agora escreve o que você falou. Pode ser na forma de conta, ou como você me falou. Do jeito que você consegue escrever o que me falou.

LAf(35;5) Fez as seguintes operações:

$200 \lcm{10} \quad 200 \lcm{10}$

$00 \quad 20 \quad 00 \quad 20$

$200 \lcm{10}$

0020 
(Em seguida fez a seguinte multiplicação)

20

$\times 3$

60

[...]

P - Ok. Então como é que você faz?

[...]

(Fez a seguinte operações):

30

$\times 2$

60

Nos trechos dos registros verbais, pode-se perceber que LAf $(35 ; 5)$ buscou apoio em $10 \%$ para, a partir daí, compor sua resposta, tanto pela via do operador (.2) (10\% de 200 é $20 ; 20 \%$ é 40 e 30\% , 60) como pela via da soma de parcelas iguais $(10 \% ; 10 \%+10 \%=20 \%+10 \%=30 \%$; e mesmo $20+20+$ $20=60$ ). É interessante observar que, no registro numérico aritmético do cálculo aparece a divisão reiterada de 200 por 10 , seguida da multiplicação de 20 por 3. Esta forma de divisão mostra que o participante decompôs o $30 \mathrm{em}$ três partes iguais (10), compondo o resultado a partir da soma dos quocientes.

$\operatorname{EPm}(22 ; 11)$ também efetuou um registro numérico aritmético. Ao explicar o porquê de sua multiplicação $(30 \times 2=60)$, informou que o 2 se refere ao 200 e que são duas vezes 100. Aqui, a quantidade inicial (200) foi decomposta em duas partes iguais (100 e 100). Como se trata de uma porcentagem (30\%), toma-se 30 de cada 100. O participante ainda não conseguiu operar algoritmicamente com a relação entre a taxa percentual e a quantidade inicial, mas dá indícios de que começa a estabelecer uma relação entre a taxa percentual e a centena, o que se constitui num referencial fundamental ao processo de conceitualização.

$\operatorname{EPm}(22 ; 11)$ fez a leitura do problema 2. Em seguida, o pesquisador interferiu com a pergunta: O que o problema diz? A resposta de $\operatorname{LAf}(35 ; 5)$ foi: que o cara recebe $R \$ 500,00$ e está defasado em $R \$ 200,00 . \operatorname{EPm}(22 ; 11)$ fala: Defasado é aumento. LAf(35;5) discorda e fala: Não. Defasado é que falta. Ele tinha que receber $R \$ 700,00$. 
Estes registros verbais orais mostram que a mediação se estabeleceu na tríade, o que aconteceu também nos Estudos II e III. Primeiramente, procurou-se compreender o enunciado do problema, para depois iniciar o processo de solução e efetuar o registro matemático. Passada esta fase, $\operatorname{EPm}(22 ; 11)$ efetuou a divisão de 500 por 100 , obtendo 5 como quociente. LAf(35;5) fez duas operações de divisão (500:200), obtendo respectivamente os quocientes 4 e 2. Inconformado com o resultado de tais divisões, dividiu 250 por 50 , obtendo 410 como quociente. Ao ser questionado sobre o porquê da divisão de 250 por 50, falou: É que 250 é metade, 50\%. Ambos afirmaram que deve ser menos de $50 \%$, uma vez que a defasagem é de $\mathrm{R} \$ 200,00$. Tem-se novamente presente a ideia de estimativa.

Os registros verbais escritos dos participantes quando da operação de divisão podem ser vistos como registros de representação semiótica numérico aritméticos, porque são constituídos por números.

O pesquisador retomou a divisão efetuada por $\operatorname{EPm}(22 ; 11)$ e perguntou o que significava o 5 . Ambos responderam que se referia a $R \$ 5,00$. O pesquisador perguntou: Em termos de porcentagem? EPm(22;11) disse que é $1 \%$. O pesquisador perguntou: E 100\% é quanto? LAf(35;5) respondeu: É tudo. Em seguida fez o seguinte registro verbal escrito.

$\begin{array}{lr}500 & 100 \% \\ 250 \longrightarrow & \longrightarrow 50 \% \\ 500 \underset{\frac{100}{5}}{\longrightarrow} & \end{array}$

Temos um registro de representação semiótica numérico, no qual o participante utilizou o referencial metade.

$\operatorname{EPm}(22 ; 11)$ acompanhou o raciocínio de $\operatorname{LAf}(35 ; 5)$ e disse: Tem que ser menos de 50\%. Então é 40. Passou a efetuar operações de divisão (500: 40; 500 : 45); em seguida efetuou a multiplicação 40.5 = 200, e falou: Achei. É 40. Estes registros verbais escritos indicam que o participante sabe que, ao se tratar de porcentagem, as operações de multiplicação e divisão entram em cena, mas este saber ainda é insuficiente. 
O pesquisador fez a leitura do problema 3. No intuito de verificar se os participantes compreenderam o enunciado, começou a fazer perguntas. As respostas indicam que o compreenderam.

Os participantes olharam (como quem lê novamente o problema) e registraram as seguintes operações aritméticas:

$\begin{array}{ll}\mathbf{E P m}(\mathbf{2 2} ; \mathbf{1 1}) & \mathbf{L A f ( 3 5 ; 5 )} \\ 40 & 40 \\ \underline{x 8 \%} & \underline{\times 8} \\ 320 & 320 \\ 320 \quad 8 & \\ 00 \quad 40 & \text { Tá muito difícil. } \\ \text { Esse aqui pegou. } & \end{array}$

Trata-se, nos termos de Duval (1993), de registros de representação semiótica numérico aritméticos.

Os diálogos que seguiram sugerem que os participantes tomaram consciência de que o resultado encontrado não condizia com o salário do trabalhador; tanto é que acabaram dizendo que o valor encontrado é muito pouco.

O pesquisador continuou instigando por meio de perguntas, tais como: O que significa 8\%? 8\% não é equivalente a $R \$ 40,00$ ? As respostas a estas perguntas são pertinentes, mas não suficientemente esclarecedoras, tanto pelos registros verbais escritos como pelos registros verbais orais. Dando continuidade, o pesquisador remeteu os participantes aos problemas 1 e 2 (já solucionados).

Os diálogos com os participantes nos levam a afirmar que eles respondem adequadamente à pergunta do problema quando conseguem estabelecer as relações entre as partes absolutas e relativas com os todos absolutos e relativos. A resposta foi encontrada a partir das composições entre os valores já obtidos e registrados na tabela de números proporcionais, procedimento este já utilizado na solução do problema 2 . 


\section{Segunda dupla: $\operatorname{GAm}(54 ; 0)$ e STf(45;8)}

$\operatorname{STf}(45 ; 8)$ fez a leitura do problema 1 . Enquanto o pesquisador conversava com $\operatorname{STf}(45 ; 8), \operatorname{GAm}(54 ; 0)$ respondeu que seria $\mathrm{R} \$ 60,00$. $\operatorname{STf}(45 ; 8)$ concordou com a resposta de GAm(54;0).

Ao ser questionado sobre o que fez para chegar a tal resultado, $\operatorname{GAm}(54 ; 0)$ respondeu: Na prática. Assim, 200, se fosse 10, seria 20. Como é 30, 3 vezes, seria 60 . $\operatorname{STf}(45 ; 8)$ participou da conversa e falou: Eu faço 3 vezes 2 . Ao ser questionado sobre o porquê de 3 vezes 2 , uma vez que se trata de 200 e 30 , este participante deu a seguinte explicação: Porque 1 inteiro é 20. Uma parte inteira. O 1 inteiro aqui não se refere à quantidade inicial 200, mas sim a $10 \%$. Isso pode ser visto mais adiante, durante os diálogos entre o pesquisador e os participantes. O 20 é o valor relativo a este 10.

Ao solicitar que registrassem o que haviam falado, $\operatorname{GAm}(54 ; 0)$ disse que não sabia fazer, enquanto STf(45;8) fez o seguinte registro verbal escrito, o qual pode ser visto como um registro de representação semiótica numérico aritmético:

$$
\begin{aligned}
& 200,00 \\
& \times \quad 3 Q \\
& \hline 60,00
\end{aligned}
$$

O resultado da operação condiz com a resposta da pergunta do problema, no entanto não condiz com o resultado da operação efetuada. Parece-nos que se trata do que Duval (2003, p. 31) chama de "representações semióticas interiorizadas em interação com um tratamento de produção externa de representações semióticas".

STf(45;8) fez a leitura do problema 3, no entanto não o interpretou corretamente, o que pode ser percebido em sua fala: Ele pede que eu veja, de 40 , eu tenho que achar o valor que saiu $R \$ 800,00.8 \%$. Nos diálogos que seguem, $\operatorname{GAm}(54 ; 0)$ se manifesta com coerência quanto à compreensão, no entanto não consegue efetuar um registro de representação que possibilitasse chegar a uma reposta para o problema. Mensalmente, a empresa tem que depositar para seu funcionário 40 . As conversas prosseguiam e STf $(45 ; 8)$ efetuou o seguinte registro verbal escrito: 


\begin{tabular}{|c|c|}
\hline 40 & 320 \\
\hline$x 8$ & $\underline{32}$ \\
\hline 320 & 00 \\
\hline
\end{tabular}

Seguindo o raciocínio do problema anterior, este participante falou e organizou um registro de representação semiótica na forma de tabela de números proporcionais.

Acompanhando os registros verbais, GAm(54;0), que já havia percebido que $8 \%$ significa $R \$ 40,00$ e que a pergunta se referia ao salário, fez o seguinte registro verbal escrito:

$$
\begin{array}{r}
100-8=92 \\
100-8=92 \\
100-8=92 \\
100-8=92 \\
100-\frac{8}{-4} \quad 92 \\
\begin{array}{r}
40 \\
+40 \\
+400
\end{array}
\end{array}
$$

Este registro indica que o participante buscou apoio na quantidade inicial 100 -reiteradamente, tirou 8 de cada 100, de forma a obter os 40 . Este participante lançou mão, ao mesmo tempo, da composição e da decomposição dos valores numéricos.

Mais uma vez, STf $(45 ; 8)$ fez a leitura do problema: agora, o problema 2. As falas deste participante indicam que ele compreendeu o enunciado, enquanto GAm(54;0) apenas acompanhava os diálogos. STf(45;8) foi pensando e, ao mesmo tempo, falando:

Se 500. Vamos fazer por mil inteiro. 1.000 inteiro. Vamos supor 10\%, que seria igual a 100. 100 mais 500 é igual a 50. (Foi efetuando o registro na forma de tabela, conforme consta a seguir). $5 \times 2$ 10. Ele deixou de receber na verdade, 500 divido por 10 dá 50. 250 daria 50\% do salário dele. Então, ele deixou de receber, na verdade, se fosse 100. Se fosse 100\%, igual a 500.50\%, é igual 250, tá. Então vamos tirar esse 50 aqui. 25\%. Quanto que é $10 \%$ de 50? É R\$5,00. 5. Vamos ver se vai bater isso aqui? Vezes, tem que dar 200 ou a divisão desse tem que dar 500, ou vezes, tem que dar 500. 10, 20, 30, 40, 50, 60, 70, 100. Dá250. $R \$ 250,00$ (foi contando nos dedos). 50\%. Só que tem que ser 200 , que seria. 
Tirando 50.

$\begin{array}{rlrl}1000 & 10 \% & =100: 2500 \\ 500 & 10 \% & =50 \\ 50 & 10 \% & =50 \\ 500 & 100 & =500 \\ x & 5,0 & =2,50,00\end{array}$

$\operatorname{GAm}(54 ; 0)$ acompanhou o raciocínio de $\operatorname{STf}(45 ; 8)$ e contribuiu fornecendo os resultados das operações mencionadas. É interessante observar que STf(45;8) tomou como apoio outros valores, neste caso, 1.000 e $10 \%$; e metade. Fez o registro de uma letra, que possivelmente se refere a um valor desconhecido (incógnita). Para este participante, o referencial metade é bastante forte; tanto é que aparece novamente no registro verbal escrito, mais especificamente na passagem de 1.000 para 500.

O valor 1.000 refere-se ao todo, sobre o qual o participante buscou o valor correspondente a $10 \%$, ou seja, 100. Este todo é divido em duas partes iguais (500), que passam a ser o novo todo, do qual o participante encontrou $10 \%$, ou seja, 50 . O todo 500 é transformado em 50 . Sobre o 50 , o participante buscou encontrar $10 \%$, o que corresponde a 5 , mas escreveu 50 .

Este participante utilizou o registro de representação semiótica numérico aritmético organizado na forma de tabela de números proporcionais. Também fez uso da incógnita " $x$ ".

\section{Terceira dupla: SCf(54;11) e ELm(37;11)}

Inicialmente, o pesquisador orientou os participantes a preencherem os dados e solucionarem os problemas. Em seguida, fez a leitura do problema. Logo após a leitura ELm(37;11), fez os seguintes registros verbais e escritos:

Qual seria o aumento. Então seria. Daí temos que pegar, pra fazer 1\%, temos que pegar 200 e dividir por 100. Duzentos, daí não precisa botar os reais porque nós vamos fazer a divisão. Cento.

$$
\begin{aligned}
& 200 \quad 100 \\
& 2=1 \% \\
& \times 3 \\
& 60,00
\end{aligned}
$$


O aumento seria de $R \$ 60,00$.

(Foi falando enquanto escrevia a resposta) Aqui nós podemos cortar os dois zeros, que fica $2 \%$. Pra saber o trinta, fazemos vezes $3.3 \times 2$, 6.).

O registro verbal escrito, no qual aparece a operação de divisão, se trata de um registro de representação semiótica numérico aritmético, a partir do qual o participante buscou encontrar o valor correspondente a 1\%, ou seja, a taxa percentual unitária. SCf $(54 ; 11)$ acompanhou os registros verbais e escritos de $\operatorname{ELm}(37 ; 11)$ e em seguida fez o seguinte registro:

$200: 100=2,00$

$3 \times 2=60,00$

$O$ aumento foi de $R \$ 60,00$.

O fato de os dois participantes efetuarem a divisão de 200 por 100 é um forte indício de que eles estabeleceram a relação da porcentagem com a centena. Podemos também dizer, nos termos de Damm (1998), que eles fizeram a avaliação da quantidade inicial (200) com a centena. É essa avaliação que caracteriza a porcentagem.

O fato de terem encontrado o valor correspondente a $1 \%$ demonstra que estes participantes fizeram uso de uma estratégia típica do processo de escolarização. Em diferentes momentos das entrevistas, os participantes mencionaram e fizeram uso do valor correspondente a $1 \%$. Isto apareceu na entrevista realizada com os professores e com os participantes da segunda dupla deste estudo. Os registros verbais orais dão indícios de que se trata mais de um algoritmo do que do resultado da compreensão. Podemos dizer que se trata de reforçar o que foi aprendido durante o processo de escolarização, ou seja, são as reminiscências escolares de que nos fala Fonseca $(2001,2002)$.

$\operatorname{SCf}(54 ; 11)$ fez a leitura do problema 2. Em seguida falou: ele recebe $R \$$ 500,00 e está defasado em $R \$ 200,00$. Seguiram-se os diálogos entre o pesquisador e os participantes e este participante fez a pergunta: O 100\%? Ele mesmo respondeu: é o 500 . A partir disso, $\operatorname{ELm}(37 ; 11)$ afirmou que é $20 \%$.

$\operatorname{SCf}(54 ; 11)$ acompanhou o raciocínio utilizado por $\operatorname{ELm}(37 ; 11)$ e efetuou o seguinte registro verbal escrito: $500,00=500: 100=5,00=1 \%$. Em seguida falou: Dividindo 500 por 100 dá 5 . 
O registro mostra que este participante dividiu o todo absoluto (500 - quantidade inicial) pelo todo relativo (100\% - taxa percentual), obtendo o valor correspondente a $1 \%$, ou seja, 5 . Temos um registro de representação semiótica numérico.

As conversas prosseguiram e ELm(37;11) refez seu cálculo, efetuando o seguinte registro verbal escrito:

$500 \lcm{100}$

$5 \quad 1 \%$ de 500.

Aqui o participante explicitou que $1 \%$ é equivalente a $\mathrm{R} \$ 5,00$.

Os diálogos continuaram e novos registros foram efetuados. Acompanhando os diálogos, é possível perceber que $\operatorname{ELm}(37 ; 11)$ reconheceu que a defasagem era de $40 \%$, tanto é que procurou uma operação para a qual conhece o algoritmo, falando o seguinte: Porque aqui é 5. $R \$ 5,00$, daí eu faço $5 \times 4$, vai dar o 200. Em seguida, reconheceu que 200 não é o produto entre 5 e 4 e disse que este é 40 .

A divisão efetuada por $\operatorname{SCf}(54 ; 11)(200: 5=40)$ passou a confirmar a resposta já obtida por ELm(37;11). O algoritmo da operação de divisão justificou o que os participantes procuravam: uma operação com os números do enunciado do problema e que resultasse em 40. A busca do algoritmo também pode ser vista como reminiscência da matemática escolar, de que trata Fonseca (2001, 2002).

Na sequência dos diálogos, e a partir do valor correspondente à unidade percentual, os participantes organizaram tabelas que expressam igualdades. Trata-se de registros numéricos na forma de tabela de números proporcionais.

O pesquisador fez a leitura do problema 3. As conversas dos participantes indicaram que eles compreenderam o enunciado do problema. Ambos partiram para o registro dos cálculos. Novamente, buscaram encontrar o valor correspondente a $1 \%$, conforme pode ser visto no recorte do protocolo a seguir. 
Participante SCf(54;11)

Tem que dividir os 40 por 8 .

\section{\begin{tabular}{l|l}
40 & 8 \\
$\underline{40} \quad 5=1 \%$
\end{tabular}}

00

$5 \times 100=500,00$.

\section{Participante ELm(37;11)}

8

$\times 10$

$80 \%=400,00$

$20 \%=100,00$

500,00
400
$\frac{8 Q}{5=1 \%}$
$\times 20$
100

$4 \theta \theta \frac{1 \theta \theta}{4}$

$\frac{\times 2}{8}$

A partir da relação de equivalência $8 \%=\mathrm{R} \$ 40,00, \operatorname{SCf}(54 ; 11)$ efetuou a divisão $(40: 8=5)$ encontrando assim o valor equivalente a $1 \%$. O produto do quociente 5 pelo todo relativo (100\%) permitiu que este participante encontrasse o resultado, da seguinte forma: $5 \times 100=500,00 . \mathrm{ELm}(37 ; 11)$ multiplicou 8 por 10 , obtendo $80 \%$, o que é equivalente a $\mathrm{R} \$ 400,00$. Para isso, fez uso do operador produto ou coeficiente de proporcionalidade (10). O equivalente aos $20 \%$ restantes só foi conseguido a partir dos diálogos e das orientações do pesquisador. Dividiu-se 400 por 80, obtendo 5 (equivalente a 1\%) e multiplicou-se o resultado por 20 , obtendo então valor de $\mathrm{R} \$ 100,00$, que adicionado aos $R \$ 400,00$, perfazendo os $100 \%$ do salário, que corresponde a $R \$ 500,00$.

Os registros verbais orais e escritos dessa dupla de alunos dão indícios de que estão familiarizados com os registros de representação semiótica e com os procedimentos difundidos pelo processo de escolarização, embora ainda não possuam amplo domínio das regras de significado e funcionamento (Duval 1993 ; 1995) da escrita matemática. Além dos registros de representação numérico aritméticos, bastante presentes nos três estudos realizados (com mais destaque entre os estudos com os alunos), esta dupla lançou mão de registros de representação semiótica na forma de fração. 


\section{Quarta dupla: AAf(38;4) e EFf(25;8)}

O pesquisador fez a leitura do problema 1. Em seguida, perguntou: $o$ que significa $30 \%$ ? EFf(25;8) falou:

Fosse 10\%, daria 20. [...] Fosse 20\%, daria 40; fosse 30\%, 60. [...] O negócio é a montagem. Eu faço isso de cabeça.

Ao ser orientado a escrever do jeito que falou, este participante fez o seguinte registro verbal escrito:

Se fosse $10 \%$ daria $R \$ 20,00$

$$
\begin{array}{lll}
20 \% & \text { “ } & R \$ 40,00 \\
30 \% & \text { “ } & R \$ 60,00
\end{array}
$$

Tanto no registro verbal oral quanto no registro verbal escrito (registro numérico de números proporcionais) de $\operatorname{EFf}(25 ; 8)$ percebemos a utilização da estratégia escalar. Nos momentos que se seguiram, os participantes dialogaram entre si. Em suas conversas, $\operatorname{AAf}(38 ; 4)$ falou que $\operatorname{EFf}(25 ; 8)$ usou a lógica, mencionou que seria interessante encontrar $1 \%$ para depois somar. Trata-se da busca de apoio nas orientações passadas pelo professor de matemática em sala de aula - ou ainda, novamente nas palavras de Fonseca (2001, 2002), trata-se das reminiscências escolares.

$\operatorname{AAf}(38 ; 4)$ fez a leitura do problema 2. $\operatorname{EFf}(25 ; 8)$ retomou a ideia do equivalente a $1 \%$. $\operatorname{AAf}(38 ; 4)$ lembrou-se do problema do avião (problema trabalhado em sala de aula). Estes são os pontos de apoio que os participantes buscaram para encontrar a resposta ao problema em questão. O que estamos falando pode ser visto no recorte do protocolo, a seguir.

$O$ registro efetuado por $\operatorname{AAf}(38 ; 4)$ mostra que este participante estabeleceu uma relação de correspondência entre 100, 20\% e 40\%. Pela via da composição, organizou os dados e chegou ao todo absoluto (500) e ao todo relativo $(100 \%)$, concluindo que $500=100 \%$, assim como $200=40 \%$. O registro verbal escrito e os registros verbais orais deste participante permitiram este entendimento. Temos aqui o registro de representação na forma de tabela de números proporcionais. 


\begin{tabular}{|c|c|c|}
\hline Pesquisador & Participante AAf(38;4) & $\begin{array}{c}\text { Participante } \\
\text { EFf }(25 ; 8)\end{array}$ \\
\hline $\begin{array}{l}\text { Se } 500 \text { é } 100 \% \text {, } \\
\text { porque você } \\
\text { quer dividir por } \\
200 ?\end{array}$ & 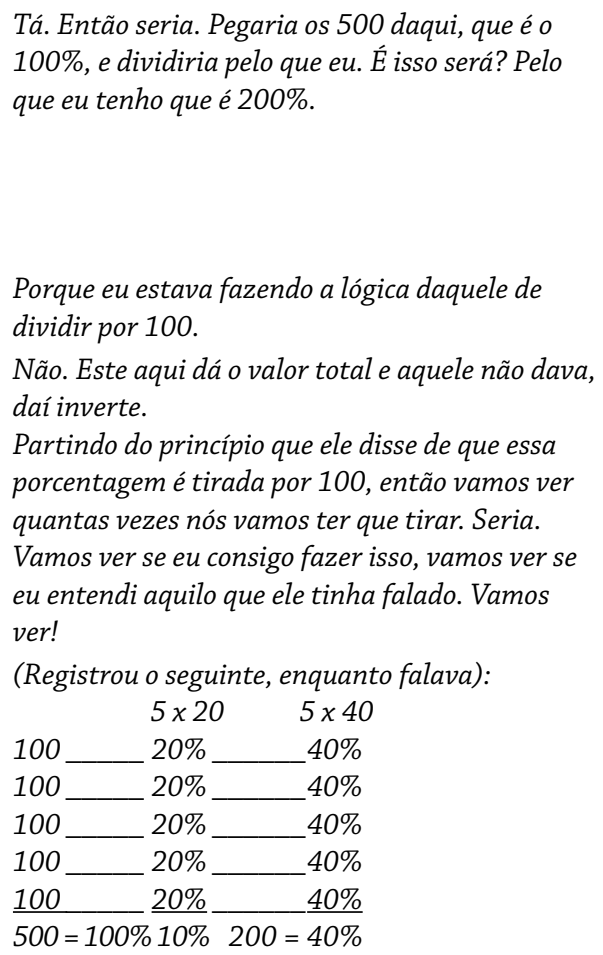 & Mas não dá. \\
\hline
\end{tabular}

De maneira muito breve, podemos dizer que os participantes desta pesquisa buscaram apoio em vivências escolares, ou ainda em valores ou quantidades que lhes fossem mais acessíveis, como metade, 50\%, 10\%, dobro, entre outros; eles fizeram uso de registros de representação semiótica numérico, principalmente aritméticos.

\section{O DESVELAR DOS RESULTADOS}

Os registros verbais orais e escritos dos participantes do Estudo IV, assim como dos participantes dos Estudos I, II e III, indicam a busca de apoio em situações socioculturais e escolares. Isto é, para solucionar os problemas propostos, os participantes procuraram estabelecer relação entre os dados e as informações presentes nos enunciados dos problemas com quantidades ou taxas percentuais que lhes fossem mais acessíveis. 
No que concerne aos registros de representação semiótica (Duval 1993; 1995; 2003), os participantes deste estudo fizeram uso, principalmente, de registros de representação semiótica numéricos, com destaque para os registros aritméticos e para a tabela de números proporcionais. $\mathrm{O}$ registro numérico na forma de tabela de números proporcionais foi utilizado pelas duplas de alunos nos quatro estudos, o que nos levou a acreditar que estes participantes percebem que existe uma relação entre as quantidades e as variáveis presentes no enunciado. Diferentemente dos Estudos I e II, no Estudo IV foram encontrados registros escritos em que a incógnita foi representada por uma letra de nosso alfabeto (x), o que pode ser visto no registro escrito (registro de representação semiótica na forma de tabela de números proporcionais) da solução do problema 2. Isso denota que o processo de escolarização amplia a gama de conhecimentos dos alunos, permitindo que eles passem a utilizar registros de representação semiótica mais elaborados, como, por exemplo, registros algébricos na forma de equação ou função.

Esses resultados apontam para a necessidade de o professor propor situações que levem os alunos a efetuar as devidas conversões, coordenando as transformações entre os sistemas de registros de representação semiótica.

\section{ALGUMAS CONSIDERAÇ̃̃ES}

Quando da elaboração da dissertação de mestrado (VIZOLLI, 2001), identificamos os registros em língua natural, numéricos (aritmético, fracionário, decimal, percentual), tabela com números proporcionais, geométricos e gráficos cartesiano. Ao aprofundar os estudos sobre registros de representação semiótica (VIZOLLI, 2006) identificamos ainda os registros algébricos na forma de equação e função.

Percebemos que os alunos fizeram uso principalmente de registros de representação semiótica mistos (combinação de linguagem natural escrita e números) e de registros numérico aritméticos. Quando instigados ou orientados fizeram uso da tabela de números proporcionais. Nesse sentido, uma das tarefas do professor é considerar que um enunciado pode auxiliar ou não o aluno no processo de compreensão conceitual, daí a necessidade da utilização 
de vários registros de representação para um mesmo objeto matemático, além da subsequente conversão entre eles. No processo de conversão é importante que se dê atenção à coordenação, porque é na passagem de um registro de representação para outro que podemos identificar os conhecimentos mobilizados no processo de solução.

Em algumas ocasiões os registros de representação utilizados pelos participantes não foram suficientes para esclarecer os conhecimentos mobilizados, principalmente quando se tratava de representações semióticas já internalizadas. Neste caso, o registro verbal oral forneceu elementos que nos permitiram saber um pouco mais sobre a forma como os participantes pensavam para solucionar o problema e a compreensão que demonstraram sobre o registro efetuado. Isso nos levou a considerar a fala como um instrumento de mediação entre o participante e o pesquisador, entre os participantes e o registro por ele utilizado e entre o pesquisador e o registro efetuado pelo participante. Por meio da fala, os participantes foram levados a pensar sobre o pensado, falar sobre o pensado, pensar e falar sobre o registrado. $O$ pesquisador foi levado a analisar o registrado e o falado, inferindo posteriormente sobre o pensamento do participante. Esta situação deveria ser uma prática permanente no processo de ensino e aprendizagem.

Durante o processo de solução dos problemas ficou patente, principalmente com os alunos, o uso de registros numérico aritméticos com tratamentos inerentes às operações fundamentais. Para os alunos, o uso da regra de três, assim como o costume de encontrar o valor correspondente à unidade percentual, não passava de uma forma ou método para solucionar os problemas. Dificilmente eles conseguiam estabelecer as devidas relações entre as quantidades e a taxa percentual, isto é, reconhecer a proporção.

Os resultados da pesquisa confirmam a hipótese de que escutar as falas, notações ou registros de representação efetuados por alunos e professores pode nos auxiliar a compreender como os participantes articulam os dados e as informações de modo a solucionar os problemas de matemática que lhes são propostos em sala de aula, o que pode nos permitir uma aproximação contínua entre o ensino e a aprendizagem. 
Considerando esse processo como um todo, estamos convictos de que precisamos de novos estudos, novas reflexões e novas pesquisas para darmos mais coerência e consistência ao fazer pedagógico de sala de aula, especialmente na EM e na EJA.

\section{REFERÊNCIAS}

ALMOULOUD, S. A. Registros de representação semiótica e compreensão de conceitos geométricos. In : MACHADO, S. A. D. (Org.). Aprendizagem em matemática: registros de representação semiótica. Campinas: SP, Papirus, 2003. p. $125-148$.

BITTAR, M. O ensino de vetores e os registros de representação semiótica. In: MACHADO, S. D. A. (Org.). Aprendizagem em matemática: registros de representação semiótica. Campinas, SP: Papirus, 2003. p. 71-94.

CARRAHER, T. N.; CARRAHER, D. W. e SCHLIEMANN, A. D. Matemática escrita versus matemática oral. In: CARRAHER, T. N.; CARRAHER, D. W.; SCHLIEMANN, A. D. Na vida dez, na escola zero. 2. ed. São Paulo: Cortez, (1988). p. 45-67.

CARVALHO, D. L de. A interação entre o conhecimento matemático da prática e o escolar. 1995. Tese (Doutorado) - UNICAMP, Campinas, 1995.

DAMM, R F. Apprentissage des prblèmes additifs et compréhesion de texte. 1992. Tese (Doutorado) - ULP, Stradbourg, 1992.

. Registros de representação. In : MACHADO, S. A. D. (Org.). Educação matemática: uma introdução. São Paulo: EDUC, 1999. p. 135-154.

. Representação, compreensão e resolução de problemas aditivos. In: MACHADO, S. D. A. (Org.). Aprendizagem em matemática: registros de representação semiótica. Campinas, SP: Papirus, 2003. p. 35-48.

DAMM W. L. Les problemes de pourcentage: une application des problèmes de conversion proportion-quantité. 1998. Annales de Didactique et de Sciences Cognitives. Strasbourg: IREM, 6, p. 197-212. 
DUARTE, N. A relação entre o lógico e o histórico no ensino da matemática elementar. 1987. (Dissertação de Mestrado) - UFSCar, São Carlos, 1987.

DUVAL, R. Registres de représentation sémiotique et fonctionnements cognitif de la pensée. In: Annales de didactique et Sciences Cognitives. Strasbourg: IREM-ULP, 1993, v. 5, p. 37-65.

. Sémiosis et pensée humaine: registres sémiotiques et apprentissages intellectuels. Bern, Berlin, Frankfurt, New York, Paris, Wien: Peter Lang, editions scientifiques européennes, 1995.

- Registros de representações semióticas e funcionamento cognitivo da compreensão em matemática. In: MACHADO, S. A. D. (Org.). Aprendizagem em matemática: registros de representação semiótica. Campinas, SP: Papirus, 2003. pp. 11-34.

FONSECA, M. da C. F. R. Discurso, memória e inclusão: reminiscências da matemática escolar de alunos adultos do ensino fundamental. 2001. (Tese de doutorado) - UNICAMP, Campinas, 2001.

Educação matemática de jovens e adultos: especificidades, desafios e contribuições. Belo Horizonte: Autêntica, 2002.

MARANHÃO, M. C. S. A.; IGLIORI, S. B. C. Registros de representação e números racionais. In: MACHADO, S. D. A. (Org.). Aprendizagem em matemática: registros de representação semiótica. Campinas, SP: Papirus, 2003. p. 57-70.

NEHRING, C. M. Compreensão de texto: Enunciados de problemas multiplicativos elementares de combinatória. 2001. Tese (Doutorado em Educação) - UFSC, Florianópolis, 2001.

VIZOLLI, I. Registro de representação semiótica no estudo de porcentagem. 2001. Dissertação (Mestrado em Educação) - UFSC, Florianópolis, 2001.

VIZOLLI, I. Registros de alunos e professores de Educação de Jovens e adultos na solução de problemas de proporção-porcentagem. Tese (Doutorado em Educação) - UFPR, Curitiba, 2006. 